\title{
Modulation of intrahepatic cholesterol trafficking: evidence by in vivo antisense treatment for the involvement of sterol carrier protein-2 in newly synthesized cholesterol transport into rat bile
}

\author{
Luigi PUGLIELLI*, Attilio RIGOTTI$, Ludwig AMIG0*, Liliana NUÑEZ*, Aldo V. GRECO†, Manuel J. SANTOS $\$$ and Flavio NERVI*\| \\ *Departamento de Gastroenterología y Centro para la Prevención y Tratamiento del Cáncer Digestivo, Facultad de Medicina, Pontificia Universidad Católica, Santiago, \\ Chile, †Istituto di Medicina Interna, Facoltá di Medicina e Chirurgia, Universitá Cattolica del S. Cuore, Roma, Italia, and ł. Departamento de Biología Celular y Molecular, \\ Facultad de Ciencias Biológicas, Pontificia Universidad Católica, Santiago, Chile
}

Biliary cholesterol represents one of the two major excretory pathways for sterol elimination from the body and plays a central role in cholesterol gallstone formation. Biliary cholesterol originates from a precursor pool of preformed and newly synthesized free cholesterol. Although it has been suggested that newly synthesized and preformed biliary cholesterol are secreted by independent pathways, the specific cellular and molecular mechanisms are unknown. We used male Wistar rats to study the time-course of the appearance of newly synthesized cholesterol, phosphatidylcholine and protein into bile. The specific role of sterol carrier protein-2 (SCP-2) in the transport of newly synthesized biliary cholesterol was evaluated by an in vivo antisense oligonucleotide approach. In contrast to $\left[{ }^{14} \mathrm{C}\right]$ phosphatidylcholine and $\left[{ }^{35} \mathrm{~S}\right]$ proteins, the time-course of $\left[{ }^{14} \mathrm{C}\right]$ cholesterol appearance into bile was rapid, and microtubule- and Golgiindependent. In vivo SCP-2 antisense treatment reduced and delayed the appearance of biliary $\left[{ }^{14} \mathrm{C}\right]$ cholesterol. Furthermore, hepatic SCP-2 expression increased more than 3-fold over control values in rats that had been treated with diosgenin to increase biliary secretion of newly synthesized cholesterol. These results suggest that SCP-2 is necessary for the rapid transport of newly synthesized cholesterol into bile and that hepatocytes can induce SCP-2 expression according to the rate of biliary secretion of newly synthesized cholesterol.

\section{INTRODUCTION}

One of the major events in cholesterol gallstone formation is the secretion by the hepatocyte of more cholesterol that can be effectively solubilized in phospholipid unilamellar vesicles and bile acid-phospholipid mixed micelles [1,2]. A significant proportion of patients with cholesterol gallstones present high rates of biliary cholesterol secretion associated with normal secretory levels of bile acids and phospholipids. This abnormality has been found in obese [3], Chilean [4] and Swedish [5] patients. It has been postulated that the mechanism(s) underlying this defect ultimately depends on the availability of free cholesterol in some hepatic precursor pool whose size would depend on the activity of other metabolic processes, including bile acid synthesis, hepatic cholesterol esterification and lipoprotein production and secretion [6]. Therefore, understanding the mechanisms by which the hepatocyte shunts free cholesterol to various metabolic and secretory endpoints will potentially shed light on this pathophysiological process.

Biliary cholesterol originates from a precursor pool of preformed and newly synthesized free cholesterol [6-10]. Newly synthesized cholesterol from hepatocytes normally represents $\sim$ $20 \%$ of total biliary cholesterol [6-10] but it can greatly increase to reach almost $50 \%$ in some high cholesterol secretory states [10-13]. Whereas preformed cholesterol seems to be in a nearcomplete equilibrium in the whole liver and bile, newly synthesized cholesterol seems to be preferentially secreted into bile [14]. Although several mechanisms have been proposed to explain hepatic cholesterol transfer from the endoplasmic reticulum (ER) to the canalicular domain of hepatocytes [15], the biliary lipid secretory pathway remains essentially unknown, compared with the lipoprotein secretory pathway to the sinusoidal mem- brane. This lack of information is principally related to the inherent methodological difficulties of tracking the intrahepatic traffic and secretion of biliary cholesterol. Moreover, intrahepatic cholesterol trafficking is probably quite complex, given that the hepatocyte is a highly polarized epithelial cell with distinctive sorting and transport systems directed both to the sinusoidal and to the canalicular domain.

We have recently shown [16] that, in cultured human fibroblasts, newly synthesized cholesterol is transferred to the plasma membrane by at least two different mechanisms: one rapid (10 $\mathrm{min}$ ), and cytoskeleton/Golgi-independent, which is directly mediated by sterol carrier protein (SCP-2); and one slower, cytoskeleton- and Golgi-dependent. We have also shown that these two routes can be modulated, and that normal cells preferentially use the rapid, SCP-2-mediated route to deliver newly synthesized cholesterol to the plasma membrane [16]. The present study was undertaken to evaluate the in vivo role of SCP-2 in hepatic cholesterol transport from the site of synthesis into bile. We used pulse-chase experiments with radioactive precursors to study the time-course of the appearance into bile of newly synthesized cholesterol, phosphatidylcholine and protein. An in vivo antisense oligonucleotide approach was used to investigate the specific role of SCP-2 in newly synthesized cholesterol transport. Finally, we analysed whether hepatocytes can increase SCP-2 expression upon receiving a stimulus to augment the secretion of newly synthesized cholesterol into bile. Our results provide novel evidence that newly synthesized hepatic cholesterol is normally transported from the ER into bile by a rapid (10 $\mathrm{min})$, SCP-2mediated route, without the involvement of the cell microtubular system and the Golgi apparatus. Finally, these results also suggest that when newly synthesized cholesterol transport into bile increases, hepatocytes can induce SCP-2 expression.

Abbreviations used: SCP-2, sterol carrier protein-2; ER, endoplasmic reticulum; VLDL, very-low-density lipoprotein; HDL, high-density lipoprotein.

$\S$ Present address: Massachusetts Institute of Technology, Biology Department, Cambridge, MA 02139, U.S.A

|| To whom correspondence should be addressed. 


\section{MATERIALS AND METHODS}

\section{Materials}

$\left[{ }^{14} \mathrm{C}\right]$ Acetic acid (sodium salt, $56 \mathrm{mCi} / \mathrm{mmol}$ ), $\left[\right.$ methyl $\left.-{ }^{14} \mathrm{C}\right]$ choline chloride $(80 \mathrm{Ci} / \mathrm{mmol}), \quad \mathrm{L}-\left[{ }^{35} \mathrm{~S}\right]$ methionine $(>1000 \mathrm{Ci} / \mathrm{mmol})$, $\left[{ }^{3} \mathrm{H}\right]$ water $(5 \mathrm{Ci} / \mathrm{ml})$ and the Enhanced Chemiluminescence Assay were purchased from Amersham Life Science (Amersham, Bucks., U.K.). Polyethylene catheters were purchased from Clay Adams Inc. (Parsippany, NJ, U.S.A.). TLC plates and all the organic solvents were obtained from Merck (Darmstadt, Germany). The RNA purification kit, PolyAtract System 1000, was obtained from Promega Corporation (Madison, WI, U.S.A.). $\left[{ }^{32} \mathrm{P}\right] \mathrm{dCTP}$ and the membranes for Northern blots were purchased from New England Research Products (Boston, MA, U.S.A.). All the other chemical agents were obtained from Sigma Chemical Co. (St. Louis, MO, U.S.A.).

\section{Animals and diet}

Male Wistar rats (80-100 g) were subjected to a reversed light cycling for 2-3 weeks before use. The mid-dark point was set at 10:00 a.m. The animals were fed ground chow, or ground chow containing $1 \%(\mathrm{w} / \mathrm{w})$ diosgenin for 10 days. Diosgenin was dissolved in chloroform, mixed with the diet and the solvent was evaporated at room temperature for $24 \mathrm{~h}$ under a hood. The animal studies were approved by the Ethical Committee of the Catholic University of Chile.

\section{Time-course of newly synthesized cholesterol, phosphatidylcholine and protein transport into bile}

On the day of the experiments, rats were anaesthetized with intraperitoneal pentobarbital $(4.5 \mathrm{mg} / 100 \mathrm{~g}$ body weight $)$ at 8:00-9:30 a.m. The common bile duct was cannulated with a PE10 polyethylene catheter and bile specimens were obtained for basal biliary lipid determination.

At time 0 of the pulse-chase experiments, animals received either $100 \mu \mathrm{Ci}$ of $\left[{ }^{14} \mathrm{C}\right]$ acetate, $150 \mu \mathrm{Ci}$ of $\left[\right.$ methyl $\left.-{ }^{14} \mathrm{C}\right]$ choline chloride, or $2 \mathrm{mCi}$ of $\mathrm{L}-\left[{ }^{35} \mathrm{~S}\right]$ methionine in $0.5 \mathrm{ml}$ of $0.9 \% \mathrm{NaCl}$ directly into the portal vein, as precursors for biliary cholesterol, phosphatidylcholine and proteins, respectively. Then $1 \mathrm{ml}$ aliquots of sodium acetate $(60 \mathrm{mg} / \mathrm{ml})$, choline $(70 \mathrm{mg} / \mathrm{ml})$, or methionine $(50 \mathrm{mg} / \mathrm{ml})$, respectively, were injected intraperitoneally at times $10,40,70,100$, and $130 \mathrm{~min}$, for the chase. Bile was collected every $10 \mathrm{~min}$ and maintained at $4{ }^{\circ} \mathrm{C}$. The rectal temperature of the animals was maintained between 37 and $37.5^{\circ} \mathrm{C}$ throughout the experiments by means of an electric lamp.

Some animals received colchicine $(0.4 \mathrm{mg} / 100 \mathrm{~g}$ body weight $)$ or monensin ( $3.5 \mathrm{mg} / 100 \mathrm{~g}$ body weight) intraperitoneally $90 \mathrm{~min}$ before the pulse-chase experiments $[17,18]$.

\section{SDS/PAGE and fluorography}

Proteins were precipitated from whole bile with trichloroacetic acid $(7 \%, v / v)$ and delipidated with cold ethanol/diethyl ether $(1: 3, \mathrm{v} / \mathrm{v})$ prior to electrophoresis. The delipidated proteins were sedimented by low-speed centrifugation, the organic solvent was discarded and the protein pellet was dried under a $\mathrm{N}_{2}$ stream. Then, biliary proteins were dissolved in sample buffer and subjected to electrophoresis on $9 \%$ polyacrylamide/SDS gels (SDS/PAGE) according to the method of Laemmli [19]. Fluorography was performed as described elsewhere [20].

\section{Preparation of liposomes and incorporation of SCP-2 antisense} oligonucleotides

Phosphodiester oligonucleotides, including SCP-2 antisense (5'AACCCATTCTGTAGAG-3'), sense (5'-CTCTACAGAATGGGTT-3'), and missense (5'-AATTCAACTCTGTTC-3'), were synthesized by Chiron Corporation (Emeryville, CA, U.S.A.), and purified on reverse-phase HPLC. Liposomes composed of cholesterol, phosphatidylcholine, phosphatidylserine and lactosylceramide $(10: 8: 2: 2$, molar ratio) were dissolved in chloroform/methanol $(2: 1, \mathrm{v} / \mathrm{v})$, evaporated under nitrogen and stored at $-20^{\circ} \mathrm{C}$ as described [15]. Samples $(40 \mu \mathrm{g})$ of the dried lipids were resuspended in $1.5 \mathrm{ml}$ of $\mathrm{PBS}(\mathrm{pH} 7.2)$, containing $1 \mathrm{mg} / \mathrm{ml}$ of the oligonucleotides, by gentle vortexing and brief sonication pulses (15-30 s) in a bath-type sonicator [21]. The oligonucleotide dose was chosen based on previous reports from other groups [22-24]. Liposomes were then diluted to $3 \mathrm{ml}$ with $0.9 \% \mathrm{NaCl}$, stored at $4{ }^{\circ} \mathrm{C}$, and used on the same day of preparation. To measure the amount of oligonucleotides encapsulated in the liposomes, a small aliquot of the sample (including trace amounts of $\left[{ }^{32} \mathrm{P}\right]$ oligonucleotides) was centrifuged twice at $120000 \boldsymbol{g}$ for $30 \mathrm{~min}$ at $20^{\circ} \mathrm{C}[22,23]$. From the comparison of the radioactive counts of liposome fractions and the total counts of the added oligonucleotides, the average encapsulation was found to be almost $30 \%$.

\section{SCP-2 antisense treatment in vivo}

On day 0 , male Wistar rats were anaesthetized with diethyl ether and the spleen was cut off. After splenectomy, the animals were allowed free access to water and control chow. On day 10, the animals were anaesthetized with diethyl ether and a tail vein was cannulated with a PE-10 polyethylene catheter. The rats were then placed in individual tubular restraining cages, continuously infused with $0.9 \% \mathrm{NaCl}$ at the rate of $1.5 \mathrm{ml} / \mathrm{h}$, and allowed free access to water and ground chow. A $1 \mathrm{ml}$ aliquot of liposomes (16 $\mu \mathrm{mol}$ of lipids) containing antisense, sense or missense oligonucleotides was injected every $8 \mathrm{~h}$ for days, and on day 15 the animals were pulse-chased with $\left[{ }^{14} \mathrm{C}\right]$ acetate. The oligonucleotides were injected for up to 5 days based on our previous results in cultured fibroblasts [16].

\section{Immunoblotting of rat liver SCP-2}

At the end of each experiment, the animals were bled, and their livers were excised and washed with $0.9 \% \mathrm{NaCl}$. A $1 \mathrm{~g}$ sample of liver was minced and homogenized in $0.25 \mathrm{M}$ sucrose, $3 \mathrm{mM}$ imidazole ( $\mathrm{pH}$ 7.4). Aliquots containing $150 \mu \mathrm{g}$ of total proteins were then dissolved in SDS gel-loading buffer [25], and analysed by Western blot [16]. Polyclonal anti-(rat SCP-2) sera binding was visualized using the enhanced chemiluminescence procedure. Densitometric analysis was performed with a CS-900 Scanner (Shimadzu Corporation, Kyoto, Japan). Anti-albumin and anti[aminopeptidase-N (EC 3.4.11.1.)] were used as controls, as previously described [25a].

\section{Northern blot analyses}

Poly(A)-tailed RNA from rat liver was isolated using an RNA Purification Kit. Rat liver cDNA probe was prepared using reverse transcription and PCR amplification [26]. Specific oligonucleotide primers were selected and synthesized by Chiron Corporation (Emeryville, CA, U.S.A.), based on the published cDNA sequence [27]. The designed oligonucleotide primers were: upstream 5'-GTGGCTCTGCAGCACAATTTA-3', downstream 5'-TGAAGCTGCAGGCTTTGCAG-3'. The probe was labelled to high specific activity $\left(1 \times 10^{9}\right.$ d.p.m. $/ \mu$ g of DNA $)$ with 
$\left[{ }^{32} \mathrm{P}\right] \mathrm{dCTP}(3000 \mathrm{Ci} / \mathrm{mM})$ using the method described by Feinberg and Vogelstein [28]. Total poly(A)-tailed RNA was subjected to electrophoresis in $1 \%$ agarose/formaldehyde gels, and transferred on to nylon membranes. After prehybridization in $5 \times$ SSPE, $50 \%$ formamide, $10 \times$ Denhardt's, $0.1 \%$ SDS, $10 \mathrm{mM}$ EDTA at $42^{\circ} \mathrm{C}$ for $2 \mathrm{~h}$, the membrane filter was hybridized overnight with the ${ }^{32} \mathrm{P}$-labelled probe, and washed for $10 \mathrm{~min}$, twice with $0.1 \times \mathrm{SSC}, 0.1 \%$ SDS at $65^{\circ} \mathrm{C}$. $[1 \times$ SSPE: $0.15 \mathrm{M}$ $\mathrm{NaCl} / 10 \mathrm{mM}$ sodium phosphate $(\mathrm{pH} 7.4) / 1 \mathrm{mM}$ EDTA; $1 \times \mathrm{SSC}: 0.15 \mathrm{M} \mathrm{NaCl} / 0.015 \mathrm{M}$ sodium citrate]. Autoradiography was performed overnight at $-80^{\circ} \mathrm{C}$. Densitometric analysis of Northern blots of SCP-2 was performed with a CS900 Scanner (Shimadzu Corporation, Kyoto, Japan) using the $\beta$ 2 microglobulin blot as denominator.

\section{Chemical analysis}

For $\left[{ }^{14} \mathrm{C}\right]$ cholesterol and $\left[\right.$ methyl $\left.-{ }^{14} \mathrm{C}\right]$ phosphatidylcholine determinations, bile was extracted with chloroform/methanol $(2: 1$, $\mathrm{v} / \mathrm{v}$ ) and the chloroform phase was dried under nitrogen. Samples were then resuspended with chloroform/methanol $(1: 1, \mathrm{v} / \mathrm{v})$ and applied together with standards to a Silica Gel-G TLC plate. Plates were developed in hexane/diethyl ether/acetic acid (87:20:1, by vol), or hexane/diethyl ether/acetic acid $(70: 30: 1$, by vol) for $\left[{ }^{14} \mathrm{C}\right]$ cholesterol $[16]$, or $\left[\right.$ methyl $\left.-{ }^{14} \mathrm{C}\right]$ phosphatidylcholine [21] determinations, respectively, and visualized with $I_{2}$ vapour. Spots were scraped and counted in a liquid scintillation counter to reach 10000 counts [16].

Biliary proteins were measured by the method of Lowry et al. [25] using BSA as standard. Biliary cholesterol, phospholipids and bile salts were quantified as previously described [29].

\section{Statistical analysis}

Data were analysed using Student's $t$ test and they were considered significantly different at the $P<0.05$ level. The values of $a$ and $b$ of the linear regressions of Figure 5 were tested for significance using the likelihood ratio test [30].

\section{RESULTS}

Effects of colchicine and monensin on the time-course of newly synthesized cholesterol, phosphatidylcholine and protein transport into bile

The first series of experiments were undertaken to examine the time-course of newly synthesized cholesterol transport into bile. To better characterize the mechanism of cholesterol transfer from its site of synthesis into bile, we also compared it with the appearance of newly synthesized biliary phosphatidylcholine and proteins.

Figure 1 shows that the kinetic curves of these biliary constituents were very different. The maximal values of biliary $\left[{ }^{14} \mathrm{C}\right]$ cholesterol were found $10 \mathrm{~min}$ after the pulse, decreasing rapidly thereafter (Figure 1A). No radiolabelled cholesterol was found $5 \mathrm{~min}$ after the pulse. It is noteworthy to point out that the maximal values of biliary $\left[{ }^{14} \mathrm{C}\right]$ phosphatidylcholine and $\left[{ }^{35} \mathrm{~S}\right]-$ proteins were found $30-40 \mathrm{~min}$ and $60-80 \mathrm{~min}$ after the pulse, respectively (Figure 1A). The protein profile shown in Figure $1(B)$ is similar to that previously described by our laboratory [25a].

To gain more insight into the mechanism of newly synthesized cholesterol transport, and to assess the possibility that the different kinetic curves found in newly synthesized cholesterol, phosphatidylcholine and protein appearance into bile could be expression of different intrahepatic transport mechanisms, some animals received colchicine or monensin before the pulse-chase
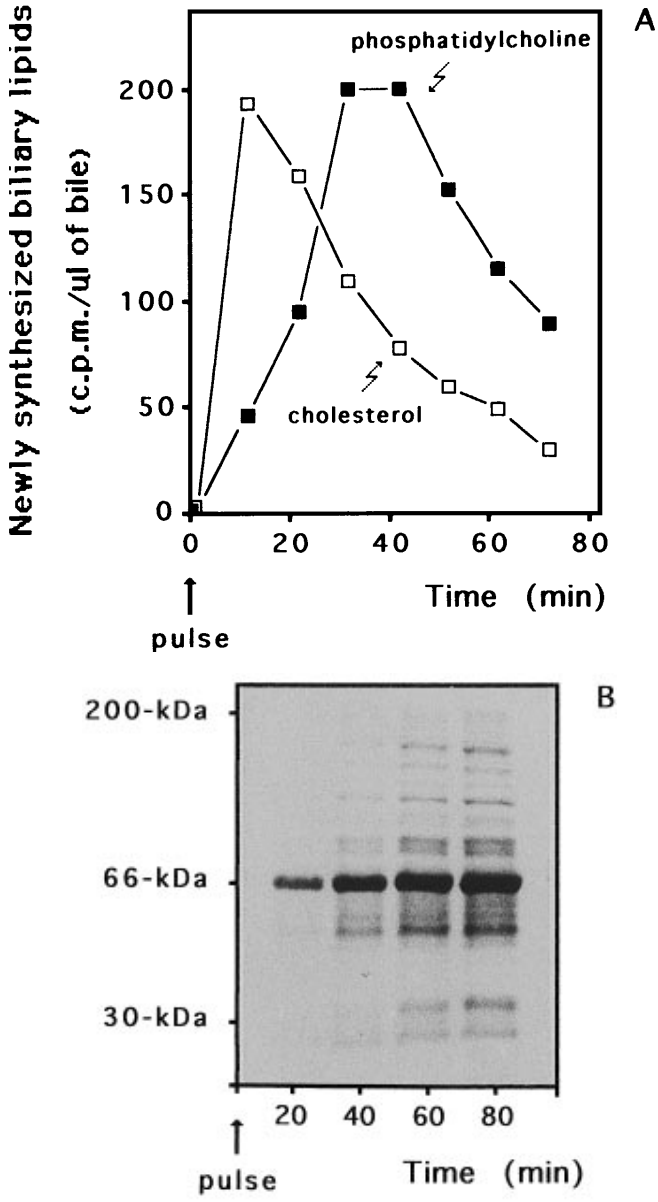

Figure 1 Time course of newly synthesized cholesterol, phosphatidylcholine and protein appearance into bile

Groups of rats received a pulse of the radiolabelled precursors $\left(\left[{ }^{14} \mathrm{C}\right]\right.$ acetate for cholesterol, $\left[\right.$ methy $\left.-l^{14} \mathrm{C}\right] c h o l i n e$ chloride for phosphatidylcholine and $\mathrm{L}-\left[{ }^{35} \mathrm{~S}\right] \mathrm{methionine}$ for proteins) at time 0 , and then they were chased for the indicated times. Bile was collected, maintained at $4{ }^{\circ} \mathrm{C}$, and processed on the same day of the experiment. (A) $\left[{ }^{14} \mathrm{C}\right]$ Cholesterol and $\left[{ }^{14} \mathrm{C}\right]-$ phosphatidylcholine appearance into bile. Results are the means of seven different experiments and are expressed as c.p.m./ $\mu$ l of bile. (B) $\left[{ }^{35}\right.$ S]Protein appearance into bile. Fluorograph of one of four different experiments is shown.

\section{Table 1 Effect of colchicine and monensin on biliary lipid secretion}

Rats were fed control chow for 10 days prior to the experiments. Colchicine or monensin were injected intraperitoneally $1.5 \mathrm{~h}$ before the experiment. Values are the mean \pm S.D. *Significant versus control.

\begin{tabular}{lllll}
\hline & \multicolumn{2}{c}{ Biliary lipid concentration $(\mathrm{mM})$} & $\begin{array}{l}\text { Bile flow } \\
\left(\mu l \cdot \mathrm{min}^{-1} \cdot g\right.\end{array}$ \\
\cline { 2 - 5 } Group & Bile salts & Phospholipids & Cholesterol & \\
of liver
\end{tabular}

experiments. The effects of both colchicine and monensin on total biliary cholesterol and phospholipid secretion are shown in Table 1. Incorporation of the radiolabelled precursors in total hepatic cholesterol and phosphatidylcholine was not affected by 

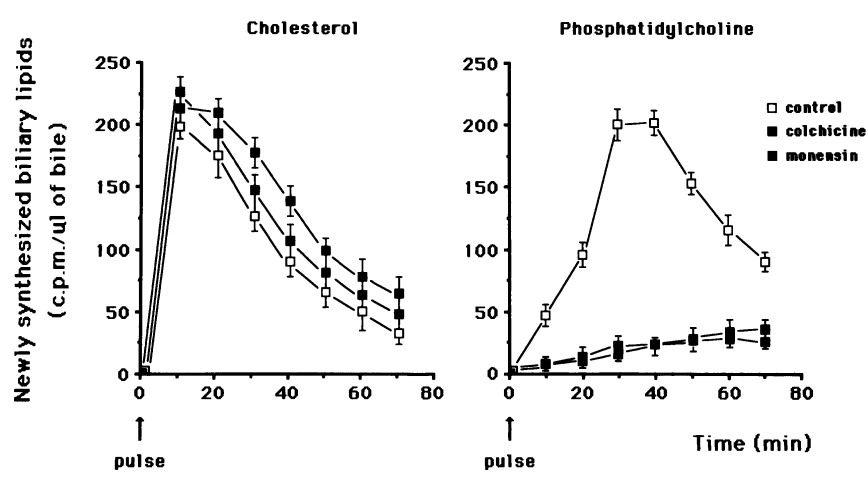

Figure 2 Effect of colchicine and monensin on the time course of $\left[{ }^{14} \mathrm{C}\right]$ cholesterol and $\left[{ }^{14} \mathrm{C}\right]$ phosphatidylcholine appearance into the bile

Groups of rats received colchicine or monensin intraperitoneally 90 min before the pulse. The pulse-chase experiments were performed as described in Figure 1. Control rats received $500 \mu \mathrm{l}$ of $0.9 \% \mathrm{NaCl}$, which was used to inject colchicine, or $100 \mu \mathrm{l}$ of ethanol, which was used to inject monensin, in the peritoneum $1.5 \mathrm{~h}$ before the pulse. Results are the mean \pm S.D. of seven different experiments and are expressed as c.p.m./ $\mu$ l of bile.

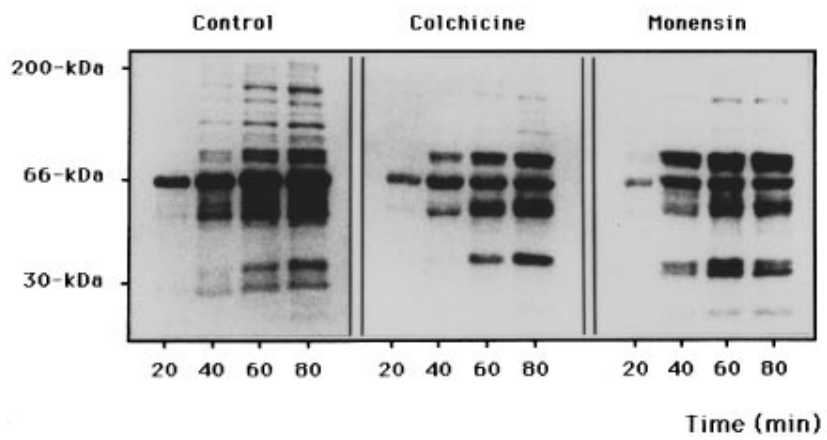

Figure 3 Effect of colchicine and monensin on the time course of newly synthesized biliary protein transport

Rats received colchicine or monensin intraperitoneally $1.5 \mathrm{~h}$ before the pulse. The pulse-chase experiments were performed as described in Figure 1, L- $\left[{ }^{35} \mathrm{~S}\right]$ methionine was used as a radiolabelled precursor for proteins. Control rats received $500 \mu \mathrm{l}$ of $0.9 \% \mathrm{NaCl}$, which was used to inject colchicine, or $100 \mu$ l of ethanol, which was used to inject monensin, in the peritoneum $1.5 \mathrm{~h}$ before the pulse. The time course of the appearance of newly synthesized protein into bile was evaluated by SDS/PAGE and fluorography. A fluorograph of one of four different experiments is shown.

colchicine or monensin pretreatment (results not shown). Although both colchicine and monensin reduced total biliary cholesterol secretion (Table 1), no changes were found in the absolute amount, or in the kinetic curve of biliary $\left[{ }^{14} \mathrm{C}\right]$ cholesterol transport (Figure 2). In contrast, the same drugs, used at equivalent concentrations, were effective in decreasing the absolute amounts and in changing the time-course of $\left[{ }^{14} \mathrm{C}\right]-$ phosphatidylcholine (Figure 2) and $\left[{ }^{35}\right.$ S]protein (Figure 3) appearance into bile. In some experiments both colchicine and monensin were used at higher concentrations, but in these conditions also no effect was seen in the absolute amount, or in the kinetic curve of biliary $\left[{ }^{14} \mathrm{C}\right]$ cholesterol transport (results not shown). Taken together, these results suggested that whereas newly synthesized phosphatidylcholine and protein secretion into bile were microtubule- and Golgi-dependent, the rapid transport of newly synthesized cholesterol from the ER into bile did not need the cellular microtubular system and could bypass the Golgi apparatus.

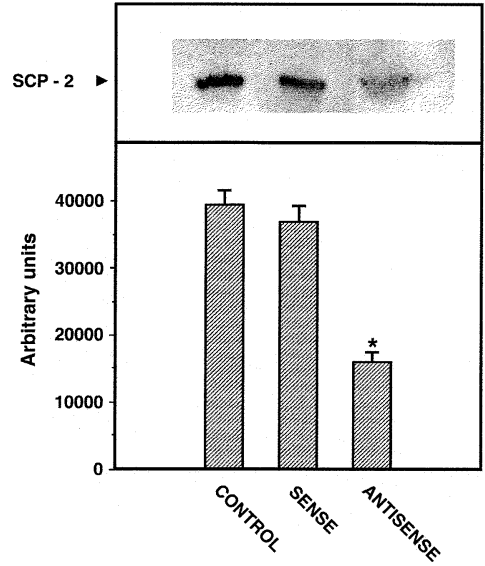

Figure 4 Effect of antisense oligonucleotide treatment on rat liver SCP-2 expression

SCP-2 antisense, sense, or missense oligonucleotides were incorporated in liposomes containing lactosylceramide, and injected into restrained rats through a tail vein for up to 5 days. Animals who received liposomes without oligonucleotides served as internal controls. Livers were excised and homogenized. Aliquots containing $150 \mu \mathrm{g}$ of protein were analysed by Western blot and the polyclonal anti-(rat SCP-2) sera binding was visualized using the enhanced chemiluminescence procedure. A Western blot of one of three different experiments is shown (upper panel). Histograms indicate relative intensities of SCP-2 bands quantified with a CS-9000 Scanner (lower panel). Values represent the mean \pm S.D. of three different experiments. The asterisk indicates a significant difference at the $P<0.05$ level.

\section{Effect of SCP-2 antisense oligonucleotide treatment in vivo}

To evaluate the possibility that SCP-2 was involved in the rapid (10 min), microtubule- and Golgi-independent transport of biliary newly synthesized cholesterol, we designed antisense oligonucleotides corresponding to the $5^{\prime}$ initiation region of the SCP2 coding sequence [27]. Oligonucleotides were incorporated in liposomes containing lactosylceramide, a glycolipid with a terminal non-reducing $\beta$-galactose residue, which has been shown to increase liposome uptake by hepatocytes [22-24]. Before antisense oligonucleotide treatment, the animals were splenectomized to reduce liposome uptake by the spleen [24]. There were no alterations in food intake, in the weights of the animals or livers, or in biliary lipid secretion in both control and oligonucleotide (antisense, sense, or missense)-treated rats. SCP-2 antisense treatment reduced the total amount of rat liver SCP-2 by almost $60 \%$, whereas treatment with control oligonucleotides (sense and missense) did not affect SCP-2 expression (Figure 4, upper and lower panels). After 5 days of antisense treatment, the animals were pulse-chased with $\left[{ }^{14} \mathrm{C}\right]$ acetate. As shown in Figure 5 , antisense treatment reduced the maximal values of biliary $\left[{ }^{14} \mathrm{C}\right]$ cholesterol by almost $45 \%$ at $10 \mathrm{~min}$ after the pulse, and induced a significant decrease of the slope of the regression line from $b=-0.65 x$ in the control to $b=-0.17 x$ in the antisensetreated rats $(P<0.002)$ (Figure 5 , inset). No difference was observed in the cumulative secretion of biliary $\left[{ }^{14} \mathrm{C}\right]$ cholesterol in control and antisense-treated animals at the end of the experiments (79.5 versus 75.3 c.p.m./ $\mu$ l of bile, respectively). These results suggested, first, that $\mathrm{SCP}-2$ was involved in the rapid and microtubule/Golgi-independent transfer of newly synthesized cholesterol from the ER into bile and, secondly, that another slower pathway was recruited in the antisense-treated rats.

\section{Effect of diosgenin feeding on liver SCP-2 expression}

To evaluate the possibility that hepatocytes could modulate 


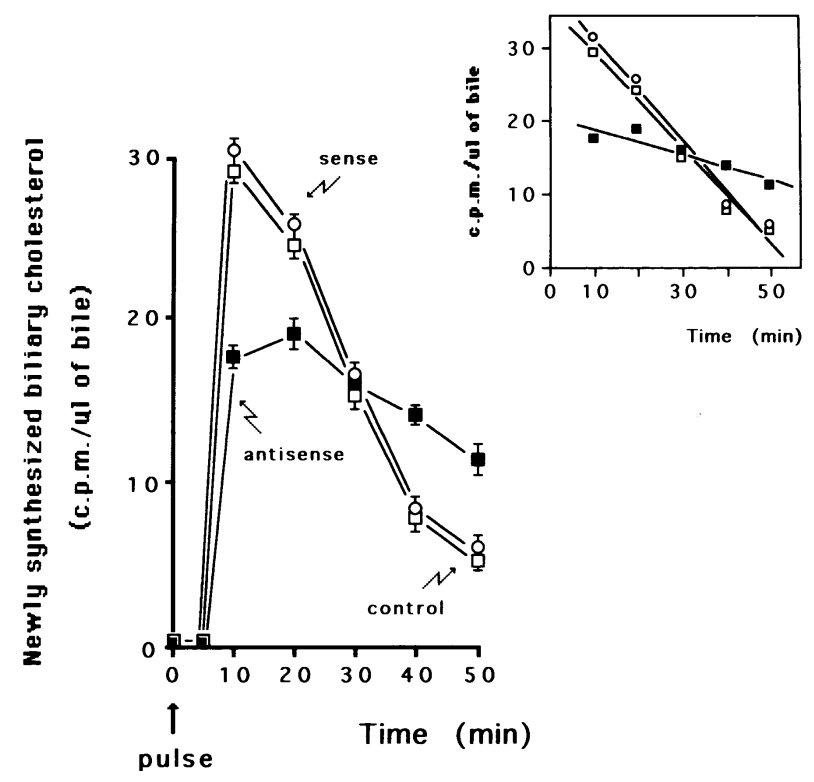

Figure 5 Effect of antisense oligonucleotides on newly synthesized hepatic cholesterol transport into bile

SCP-2 antisense, sense, or missense oligonucleotides were incorporated in liposomes containing lactosylceramide, and injected into restrained rats through a tail vein for up to 5 days. Animals that received liposomes without oligonucleotides served as internal controls. The pulse-chase experiments were performed as described in the legend of Figure 1. The incorporation rates of $\left[{ }^{14} \mathrm{C}\right]$ acetate into total hepatic cholesterol were similar in control, senseand antisense-treated animals. Results are the mean \pm S.D. of three different experiments and are expressed as c.p.m./ $\mu$ l of bile. The inset represents the regression lines between the c.p.m. values found in bile as a function of time (10 to $50 \mathrm{~min}$ ). Correlation coefficients were $r<$ $-0.95(P<0.0001)$. The slopes of the regression lines were: control, $y=35.4-0.65 x$; antisense, $y=20.3-0.17 x$; sense, $y=37.9-0.69 x$. Slope $b$ of the antisense group was decreased $74 \%$ relative to the control group $(P<0.002)$.

SCP-2 expression according to the rate of newly synthesized biliary cholesterol secretion, we studied liver SCP-2 expression in animals with increased secretion of biliary newly synthesized cholesterol [10,32]. Rats were fed a $1 \%$ diosgenin diet for up to 10 days. This diet increased both biliary cholesterol secretion $(\sim$ $500 \%$ ) and the contribution of newly synthesized hepatic cholesterol to biliary cholesterol (more than $500 \%$ ), when compared with the control diet [32]. Immunoblots from fresh liver homogenates recognized SCP-2 $(14 \mathrm{kDa})$ and its $60 \mathrm{kDa}$ peroxisomal precursor (Figure 6A) [16]. The SCP-2 cDNA fragment, which was used as a probe, recognized mRNA species of $0.8,1.4$ and $2.1 \mathrm{~kb}$ (Figure 6B). An additional transcript of $2.7 \mathrm{~kb}$ could be observed after long exposure. The predominant transcript was $0.8 \mathrm{~kb}$, as previously described [27,33,34]. Figures 6(A) and 6(B) show that SCP-2, its $60 \mathrm{kDa}$ peroxisomal precursor and the respective mRNA transcripts increased more than 3-fold over the control values in the animals with increased secretion of newly synthesized cholesterol into bile. In contrast, hepatic albumin and aminopeptidase-N Western blots were not modified by diosgenin feeding (results not shown). Taken together, these results suggested that when the mass of cholesterol transported from the ER into bile increases, hepatocytes could specifically induce SCP-2 expression.

\section{DISCUSSION}

The present results provide the first in vivo evidence for the involvement of SCP-2 in a rapid, microtubule/Golgi-independent
A

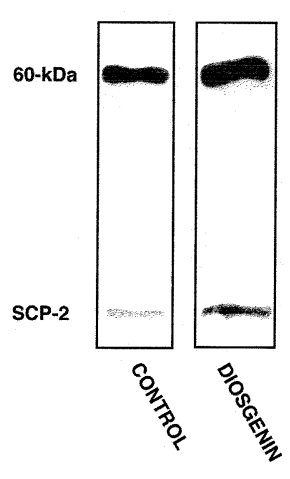

B

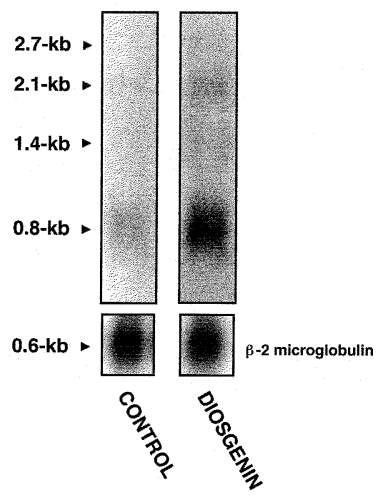

Figure 6 Immunoblot (A) and Northern blot (B) quantification of SCP-2 in fresh liver homogenates from rats with normal and increased biliary secretion of newly synthesized cholesterol

Animals were fed control chow, or ground chow containing 1\% diosgenin for 10 days before the experiments. (A) For immunoblot analysis, aliquots containing $150 \mu \mathrm{g}$ of proteins from liver homogenates were analysed as described in Figure 4. A representative immunoblot of three different experiments is shown, Western blots of hepatic aminopeptidase- $\mathrm{N}$ and albumin were similar in control and diosgenin-fed animals (results not shown). (B) For Northern blot analysis, $5 \mu \mathrm{g}$ of poly(A)-enriched RNA from rat liver was loaded in each lane. A Northern blot of one of three different experiments is shown. Densitometric analysis of both Western and Northern blots were performed with a CS-900 Scanner.

transport of newly synthesized cholesterol from the site of synthesis into bile. These results also suggest that different pathways are involved in biliary newly synthesized cholesterol, phosphatidylcholine and protein secretions, and that hepatocytes can modulate SCP-2 expression according to the rate of biliary newly synthesized cholesterol secretion.

The hepatocyte is a highly polarized cell with a sinusoidal and a canalicular domain. Cholesterol is secreted through the sinusoidal membrane assembled with apolipoproteins, and through the canalicular membrane as free cholesterol, presumably solubilized in phospholipid vesicles [15]. There is substantial evidence consistent with the presence of a functional compartment within the hepatocyte that contains phospholipids and cholesterol destined for secretion into the bile $[6,15]$. This functional compartment ultimately represents the intracellular origin of biliary lipids, and it apparently includes the endosomal-lysosomal compartment, the plasma membrane, the Golgi apparatus and the ER [6,15]. Metabolically active hepatic cholesterol originates from new synthesis, and from chylomicron or very-low-density lipoprotein (VLDL) remnants, low-density lipoprotein (LDL) and high-density lipoprotein (HDL). In non-hepatic cells, the movement of exogenously derived cholesterol to the plasma membrane seems to be distinct from the transport of newly synthesized cholesterol [35,36]. Some evidence also suggests separate pathways of transport for newly synthesized and preformed cholesterol into bile [14]. In peripheral cells, exogenously derived cholesterol has been shown to be directly delivered into the plasma membrane after lysosomal hydrolysis [35,36]. This incorporation is not mediated by SCP-2 [37] and is not affected by microtubule-disrupting drugs [35,36]. In contrast, biliary cholesterol and phospholipids are markedly decreased by inhibitors of the cytoskeleton (present results and [17,38]) and the contribution of lysosomal lipid constituents to bile seems to be low [39]. The role of the Golgi apparatus in the packing and sorting of intracellular lipids, including cholesterol, to the plasma membrane has been clearly characterized in peripheral cells 
[40-42]. It is noteworthy that ionophores, which interfere with the Golgi functions [43], decrease both the sinusoidal secretion of VLDL [44] and the canalicular secretion of cholesterol and phospholipids (present results and [18]). The ER plays a fundamental role in the regulation of intrahepatic cholesterol metabolism [6]. Despite its role in both newly synthesized and preformed cholesterol trafficking, the ER is the intracellular membrane with the lowest content of cholesterol [36,42], suggesting a continuous and rapid sterol mobilization.

Using in vivo pulse-chase experiments, we have shown that hepatic cholesterol transfer from the ER into bile is normally rapid (10 $\mathrm{min})$. This transport was not affected by colchicine or monensin. Colchicine is a well known microtubule-disrupting agent [45] and its effects on the vesicle-mediated transport of proteins and lipids have been extensively studied in cultured cells and in the whole animal $[15-17,46]$. Monensin is an ionophore that disrupts the trans-Golgi elements and inhibits the intracellular transport of membrane and secretory proteins, and some lipids $[15,16,18,43]$. Although both drugs inhibited total biliary cholesterol secretion, neither colchicine nor monensin did affect newly synthesized biliary cholesterol transfer in control rats. It is noteworthy that both newly synthesized biliary proteins and phosphatidylcholine were transported by slower, microtubule/ Golgi-dependent mechanisms. Previous studies [47] have shown that both newly synthesized apical plasma membrane and biliary proteins are first delivered to the sinusoidal membrane, via the Golgi complex, and then sorted to the apical pole, via transcytotic vesicles. The time-course of biliary $\left[{ }^{35}\right.$ S $]$ proteins appearance and the effects of both colchicine and monensin are consistent with this proposed route. On the other hand, although a rapid, protein-mediated transfer has been proposed [48,49], phosphatidylcholine is normally transported from the ER to the plasma membrane of eukaryotic cells by a vesicle-mediated mechanism $[40,41]$. Concordant with this route, putative transport vesicles enriched in phosphatidylcholine and cholesterol have been isolated $[40,41]$. In polarized cells, including hepatocytes, lipids are thought to move directly from their site of synthesis to the plasma membrane and till now there is no evidence for the movement of lipids from one plasma membrane domain to another by transcytosis [40]. We found that the maximal values of $\left[{ }^{14} \mathrm{C}\right]$ phosphatidylcholine appeared $30-40 \mathrm{~min}$ after the pulse into bile, and that the kinetic curve was dramatically affected by both colchicine and monensin. This kinetics was more rapid than that found for biliary newly synthesized proteins, which are known to be transported indirectly, via transcytotic vesicles from the sinusoidal pole [47]. Thus, our results support the view that phosphatidylcholine is directly transported from the ER into bile by vesicles which travel through the Golgi apparatus. If we consider all these results together, it can be suggested that newly synthesized cholesterol is normally transferred from the ER into bile by a direct route and without the involvement of the Golgi apparatus or the microtubular system. These characteristics are consistent with a carrier protein-mediated process [40].

We have recently shown [16] that in cultured human fibroblasts, newly synthesized cholesterol is transported to the plasma membrane by two different mechanisms: one rapid (10 min), cytoskeleton/Golgi-independent, which is directly mediated by SCP-2, and one slower, cytoskeleton/Golgi-dependent. We have also shown that the ER can modulate the two routes: when SCP2 is present, as occurs in normal fibroblasts, cholesterol is removed by the first and more rapid route; when SCP-2 is absent, as occurs in mutant cells (Zellweger syndrome fibroblasts) or after SCP-2 antisense oligonucleotide treatment, cholesterol is removed by the cytoskeleton/Golgi-dependent route [16]. In the present study we designed SCP-2 antisense experiments in vivo to determine the specific role of SCP-2 in biliary newly synthesized cholesterol secretion. Our results, support the view that SCP-2 is involved in newly synthesized cholesterol transport into bile. Antibodies raised against SCP-2 also recognize a $60 \mathrm{kDa}$ polypeptide (Figure 6), which is thought to be the SCP-2 precursor [50,51]. The antisense treatment reduced the total amount of both SCP-2 (Figure 4) and its $60 \mathrm{kDa}$ related protein (result not shown). The $60 \mathrm{kDa}$ protein localizes to peroxisomes [52] and represents an N-terminal extension of SCP-2 [50]. The functions of this protein still remain unclear and only SCP-2 appears to function as a cytosolic carrier protein for sterol molecules [35,53]. Liposome injection reduced by more than $60 \%\left[{ }^{14} \mathrm{C}\right]$ acetate incorporation into total liver cholesterol, in both control and oligonucleotide (antisense, sense, or missense)-treated animals, but did not affect biliary lipid secretion. This finding could be explained by the down-regulation of the 3-hydroxy-3-methylglutaryl CoA (HMG-CoA) reductase, expected after the intravenous administration of liposomal cholesterol. Antisense treatment reduced the rapid $(10 \mathrm{~min})$ peak of biliary $\left[{ }^{14} \mathrm{C}\right]-$ cholesterol secretion, and induced a major shift of the kinetic curve by decreasing the slope of the regression lines (Figure 5). This finding suggests the involvement of a slower and different transport mechanism. In agreement with this pattern, no difference was observed in the cumulative secretion of biliary $\left[{ }^{14} \mathrm{C}\right]-$ cholesterol in control and antisense-treated animals at the end of the experiments ( 79.5 versus 75.3 c.p.m. / $\mu$ l of bile, respectively).

We used diosgenin, a plant-derived sapogenin structurally similar to cholesterol, to increase biliary newly synthesized cholesterol secretion [10,32]. Quantitative immunoblotting showed increased amounts of rat liver SCP-2 and no changes in hepatic albumin and aminopeptidase $\mathrm{N}$ in diosgenin-fed rats, supporting the view that hepatocytes could modulate SCP-2 expression according to the rate of biliary cholesterol secretion. The levels of SCP-2 mRNA were analysed by Northern blot. We detected four mRNA species of $0.8,1.4,2.1$ and $2.7 \mathrm{~kb}$, as previously described $[27,33,34]$. The 0.8 and the $1.4 \mathrm{~kb}$ transcripts have been reported to encode a $15 \mathrm{kDa}$ protein with a 20 -aminoacid prepeptide that is post-translationally removed to form mature SCP-2 [27,50,51]. The 2.1 and the $2.7 \mathrm{~kb}$ transcripts have been suggested to encode the $60 \mathrm{kDa}$ protein [27,50,51]. The four mRNA species are generated from one gene by differential splicing and then, by alternative adenylation [27,51]. Quantitative Northern blotting showed that the animals with increased secretion of newly synthesized cholesterol into bile also had increased SCP-2 mRNA levels in the liver, suggesting a pretranscriptional mechanism in the control of SCP-2 expression. Concordantly with these observations, a recent study by Hirai et al. [33] has shown that, in rat peritoneal macrophages, SCP-2 expression could be modulated by the intracellular content of exogenously derived cholesterol, suggesting that SCP-2 is involved in the regulation of intracellular trafficking of free cholesterol. One of the major determinants of biliary cholesterol output is the availability of free cholesterol in intracellular membranes [6]. The size of this functional pool determines the amount of cholesterol effectively transported into the bile. Previous studies from our laboratory [10,32] strongly supported the concept that VLDL-cholesterol and biliary-cholesterol originate from the same ER precursor pool and are functionally interrelated. It is noteworthy that both diosgenin (present results) and fructose (L. Nunez, unpublished work) feeding, which stimulates sinusoidal VLDL-cholesterol secretion, increased SCP-2 expression. These results suggest that SCP-2 may be involved in the modulation of the specific functional pool by which both VLDL-cholesterol and biliary-cholesterol originate.

The specific mechanism by which cholesterol is translocated 
through the canalicular membrane and delivered into bile remains unclear. It may be possible that after the SCP-2-mediated transport to the inner leaflet of the hepatic canalicular membrane, cholesterol molecules rapidly migrate to the outer leaflet $[53,54]$, and then are solubilized in phospholipid vesicles, or in bile salts-phospholipid mixed micelles [15]. It is apparent, however, that after membrane translocation of cholesterol the role of the canalicular mdr-2 flippase, a phosphatidylcholine translocase, becomes critical for cholesterol secretion into bile [55,56]. Biliary cholesterol output dramatically drops in mice with disruption of the $m d r$-2 gene, indicating that the physiological dependence of cholesterol to phospholipid secretion into bile is mediated by the canalicular mdr-2 flippase [56]. Recent studies from this laboratory have shown that overexpression of the $m d r-2$ gene in mice is followed by an increase of biliary phospholipid output, but without changes in cholesterol output [57]. This observation indicates that the activity of the canalicular flippase is critical for cholesterol secretion into bile, but may not increase sterol secretion into bile. This last quantitative aspect of cholesterol secretion more likely depends on some metabolic factors, such as hepatic VLDL and HDL production, intracellular membrane traffic and bile acid synthesis [15].

The physiological and pathophysiological implications of the SCP-2-mediated cholesterol secretory pathway remain to be elucidated. It is theoretically possible that a chronic and complete impairment of SCP-2 function could ultimately affect total biliary cholesterol secretion. Our results give rise to the possibility that regulation of liver SCP-2 activity may influence both the intrahepatic cholesterol compartmentalization and sterol balance in the whole animal. Finally, it could be possible that some high biliary cholesterol secretory states, such as those associated with obesity and gallstone disease $[3,58]$, could be mediated by liver SCP-2 overexpression.

This work was supported by the Ministero degli Affari Esteri d'Italia and the Istituto per la Cooperazione Universitaria (ICU), Italy, and Fondecyt 1940620, 1940582 and 1940686, Chile. The polyclonal antibody against SCP-2 was kindly provided by Dr. Charles L. Baum (Department of Medicine, Gastroenterology Section, University of Chicago, Chicago, IL, U.S.A.) [34]. We thank L. Villaroel for statistical analysis and C. B. Hirschberg and J. F. Miquel for critical review of the manuscript. Part of this work was presented at the American Gastroenterological Association Meeting in New Orleans, L0, 1994 and published as an abstract [Gastroenterology (1994) 106, A966]. It was also presented at the Second International Conference on Gallstones: Causes and Management in Tel Aviv, Israel, 1995.

\section{REFERENCES}

1 Hofmann, A. (1990) Hepatology 12, 17S-25S

2 Strasberg, S. and Hofmann, A. (1990) Hepatology 12, 1S-5S

3 Bennion, L. J. and Grundy, S. M. (1975) J. Clin. Invest. 56, 996-1011

4 Valdivieso, V. D., Palma, R., Nervi, F., Covarrubias, C., Severin, S. and Antezana, C. (1979) Gut 20, 997-1000

5 Nilsell, K., Angelin, B., Liljeqvist, L. and Einarsson, K. (1985) Gastroenterology 89 287-293

6 Marzolo, M. P., Rigotti, A. and Nervi, F. (1990) Hepatology 12, 134S-142S

7 Turley, S. D. and Dietschy, J. M. (1988) in The Liver: Biology and Pathobiology (Arias, M., Jakoby, W. B., Popper, H. and Shafritz, D. A., eds.), pp. 617-641, Raven Press, New York, NY

8 Robins, S. J. and Brunengraber, H. (1982) J. Lipid Res. 23, 604-608

9 Turley, S. D. and Dietschy, J. M. (1981) J. Biol. Chem. 256, 2438-2446

10 Nervi, F., Bronfman, M., Allalón, W., Depiereux, E. and Del Pozo, R. (1984) J. Clin. Invest. 74, 2226-2237

11 Nervi, F., Del Pozo, R., Covarrubias, C. and Ronco, B. (1983) Hepatology 3, 360-367

12 Rigotti, A., Marzolo, M. P., Ulloa, N., Gonzalez, O. and Nervi, F. (1989) J. Lipid Res. 30, $1041-1048$
13 Marzolo, M. P., Amigo, L. and Nervi, F. (1993) J. Lipid Res. 34, 807-814

14 Robins, S. J., Fasulo, J. M., Collins, M. A. and Patton, G. M. (1985) J. Biol. Chem. 260, 6511-6513

15 Rigotti, A., Marzolo, M. P. and Nervi, F. (1994) in Current Topics in Membranes (Hoekstra, D., ed.), pp. 579-615, Academic Press, San Diego, CA

16 Puglielli, L., Rigotti, A., Greco, A. V., Santos, M. J. and Nervi, F. (1995) J. Biol. Chem. 270, 18723-18726

17 Barnwell, S. G., Lowe, P. J. and Coleman, R. (1984) Biochem. J. 220, 723-731

18 Casu, A. and Camogliano, L. (1990) Biochim. Biophys. Acta 1043, 113-115

19 Laemmli, U. K. (1970) Nature (London) 227, 680-685

20 Waterborg, J. H. and Matthews, H. R. (1984) in Methods in Molecular Biology, Proteins (Walker, J. M., ed.), pp. 147-152, Humana Press, Clifton, NJ

21 Puglielli, L., Amigo, L., Arrese, M., Nuñez, L., Rigotti, A., Garrido, J., Gonzalez, S., Mingrone, G., Greco, A. V., Accatino, L. and Nervi, F. (1994) Gastroenterology 107 244-254

22 Soriano, P., Dijkstra, J., Legrand, A., Spanjer, H., Londos-Gagliardi, D., Roerdink, F., Scherphof, G. and Nicolau, C. (1983) Proc. Natl. Acad. Sci. U.S.A. 80, 7128-7131

23 Nandi, P. K., Legrand, A. and Nicolau, C. (1986) J. Biol. Chem. 261, 16722-16726

24 Hug, P. and Sleight, R. G. (1982) Biochim. Biophys. Acta 721, 185-190

25 Lowry, 0. H., Rosebrough, N. J., Farr, A. L. and Randall, Q. J. (1951) J. Biol. Chem 193, 265-275

25a Rigotti, A., Nuñez, L., Amigo, L., Puglielli, L., Garrido, J., Santos, M., Gonzalez, S., Mingrone, G., Greco, A. V. and Nervi, F. (1993) J. Lipid Res. 34, 1883-1894

26 Saiki, R. K., Gelfand, D. H., Stoffel, S., Scharf, S. J., Higuchi, R., Horn, G. T., Mullis, K. B. and Erlich, H. A. (1988) Science 239, 487-491

27 Seedorf, U. and Assmann, G. (1991) J. Biol. Chem. 266, 630-636

28 Feinberg, A. and Vogelstein, B. (1983) Anal. Biochem. 132, 6-13

29 Ulloa, N. J., Garrido, J. and Nervi, F. (1987) Hepatology 7, 235-244

30 Mardia, K. V., Kent, J. T. and Bibby, J. M. (1981) Multivariate Analysis, pp. 121-144, Academic Press, London

31 Reference deleted

32 Nervi, F., Marinovíc, I., Rigotti, A. and Ulloa, N. (1988) J. Clin. Invest. 82 $1818-1825$

33 Hirai, A., Kino, T., Tokinaga, K., Tahara, K., Tamura, Y. and Yoshida, S. (1994) J. Clin. Invest. 94, 2215-2223

34 Baum, C. L., Kansal, S. and Davidson, N. O. (1993) J. Lipid Res. 34, 729-739

35 Liscum, L. and Dahl, N. K. (1992) J. Lipid Res. 33, 1239-1254

36 Liscum, L. and Underwood, K. W. (1995) J. Biol. Chem. 270, 15443-15446

37 Johnson, W. J. and Reinhart, M. P. (1994) J. Lipid Res. 35, 563-573

38 Crawford, J., Berken, C. and Gollan, J. (1988) J. Lipid Res. 29, 144-156

39 Coleman, R. and Rahman, K. (1992) Biochim. Biophys. Acta 1125, 113-133

40 Pagano, R. E. (1990) Curr. Opin. Cell Biol. 2, 652-663

41 Mclntyre, J. C. and Sleight, R. C. (1994) in Current Topics in Membranes (Hoekstra, D., ed.), pp. 453-481, Academic Press, San Diego, CA

42 Bretscher, M. S. and Munro, S. (1993) Science 261, 1280-1281

43 Johnson, D. C. and Schlesinger, M. J. (1980) Virology 103, 407-424

44 Rustan, A., Nossen, J., Berg, T. and Drevon, C. (1985) Biochem. J. 227, 529-536

45 Salmon, E. D., McKeel, M. and Hays, T. (1984) J. Cell Biol. 99, 1066-1075

46 Redman, C. M., Banerjee, D., Howell, K. E. and Palade, G. E. (1975) J. Cell Biol. 66 42-59

47 Bartles, J. F., Feracci, H. M., Stieger, B. and Hubbard, A. L. (1989) J. Cell Biol. 105, $1241-1251$

48 Moreau, P. and Morré, D. J. (1991) J. Biol. Chem. 266, 4329-4333

49 Cohen, D. E., Leonard, M. R. and Carey, M. C. (1994) Biochemistry 33, 9975-9980

50 Pfeifer, S. M., Furth, E. E., Ohba, T., Chang, I. J., Rennert, H., Sakuragi, N., Billheimer, J. T. and Strauss, III, J. F. (1993) J. Steroid Biochem. Mol. Biol. 47, 167-172

51 Ossendorp, B. C., Snoek, G. T. and Wirtz, K. W. A. (1994) in Current Topics in Membranes (Hoekstra, D., ed.), pp. 217-259, Academic Press, San Diego, CA

52 Seedorf, U., Brysch, P., Engel, T., Schrage, K. and Assmann, G. (1994) J. Biol. Chem. 269, 21277-21283

53 Slotte, J. P., Pörn, M. I. and Härmälä, A.-S. (1994) in Current Topics in Membranes (Hoekstra, D., ed.), pp. 483-502, Academic Press, San Diego, CA

54 Lange, Y., Dolde, J. and Steck, T. L. (1981) J. Biol. Chem. 256, 5321-5323

55 Smit, J. J. M., Schinkel, A. H., Oude Elferink, R. P. J., Groen, A. K., Wagenaar, E., van Deemter, L., Mol, C. A. A. M., Ottenhoff, R., Van der Lugt, N. M. T. and van Room, A. (1993) Cell 75, 451-462

56 Oude Elferink, R. P. J., Ottenhoff, R., van Wijland, M., Smit, J. J. M., Schinkel, A. H. and Groen, A. K. (1995) J. Clin. Invest. 95, 31-38

57 Chianale, J., Vollrath, V., Wielandt, A. M., Amigo, L., Rigotti, A., Nervi, F., González, S., Andrade, L., Pizarro, M. and Accatino, L. (1996) Biochem. J. 314, 781-786

58 Grundy, S. M., Metzger, A. L. and Adler, R. D. (1972) J. Clin. Invest. 51, 3026-3043 